\title{
An overview of the diurnal cycle of the atmospheric boundary layer during the West African monsoon season: results from the 2016 observational campaign
}

\author{
Norbert Kalthoff $^{1}$, Fabienne Lohou ${ }^{2}$, Barbara Brooks ${ }^{3}$, Gbenga Jegede $^{4}$, Bianca Adler ${ }^{1}$, Karmen Babić $^{1}$, \\ Cheikh Dione $^{2}$, Adewale Ajao ${ }^{4}$, Leonard K. Amekudzi ${ }^{6}$, Jeffrey N. A. Aryee ${ }^{6}$, Muritala Ayoola ${ }^{4}$, Geoffrey Bessardon ${ }^{3}$, \\ Sylvester K. Danuor ${ }^{6}$, Jan Handwerker ${ }^{1}$, Martin Kohler ${ }^{1}$, Marie Lothon ${ }^{2}$, Xabier Pedruzo-Bagazgoitia ${ }^{5}$, \\ Victoria Smith $^{3}$, Lukman Sunmonu ${ }^{4}$, Andreas Wieser ${ }^{1}$, Andreas H. Fink ${ }^{1}$, and Peter Knippertz ${ }^{1}$ \\ ${ }^{1}$ Institute of Meteorology and Climate Research, Karlsruhe Institute of Technology (KIT), Karlsruhe, Germany \\ ${ }^{2}$ Laboratoire d'Aérologie, Université de Toulouse, CNRS, UPS, Toulouse, France \\ ${ }^{3}$ National Centre for Atmospheric Science, School of Earth and Environment, University of Leeds, Leeds, UK \\ ${ }^{4}$ Department of Physics \& Engineering Physics, Obafemi Awolowo University, Ile-Ife, Nigeria \\ ${ }^{5}$ Meteorology and Air Quality Group, Wageningen University and Research, Wageningen, the Netherlands \\ ${ }^{6}$ Department of Physics, Kwame Nkrumah University of Science and Technology, Kumasi, Ghana
}

Correspondence: Norbert Kalthoff (norbert.kalthoff@kit.edu)

Received: 5 July 2017 - Discussion started: 21 September 2017

Revised: 12 January 2018 - Accepted: 24 January 2018 - Published: 1 March 2018

\begin{abstract}
A ground-based field campaign was conducted in southern West Africa from mid-June to the end of July 2016 within the framework of the Dynamics-Aerosol-ChemistryCloud Interactions in West Africa (DACCIWA) project. It aimed to provide a high-quality comprehensive data set for process studies, in particular of interactions between lowlevel clouds (LLCs) and boundary-layer conditions. In this region missing observations are still a major issue. During the campaign, extensive remote sensing and in situ measurements were conducted at three supersites: Kumasi (Ghana), Savè (Benin) and Ile-Ife (Nigeria). Daily radiosoundings were performed at 06:00 UTC, and 15 intensive observation periods (IOPs) were performed during which additional radiosondes were launched, and remotely piloted aerial systems were operated. Extended stratiform LLCs form frequently in southern West Africa during the nighttime and persist long into the following day. They affect the radiation budget and hence the evolution of the atmospheric boundary layer and regional climate. The relevant parameters and processes governing the formation and dissolution of the LLCs are still not fully understood. This paper gives an overview of the diurnal cycles of the energy-balance components, nearsurface temperature, humidity, wind speed and direction as well as of the conditions (LLCs, low-level jet) in the bound-
\end{abstract}

ary layer at the supersites and relates them to synoptic-scale conditions (monsoon layer, harmattan layer, African easterly jet, tropospheric stratification) in the DACCIWA operational area. The characteristics of LLCs vary considerably from day to day, including a few almost cloud-free nights. During cloudy nights we found large differences in the LLCs' formation and dissolution times as well as in the cloud-base height. The differences exist at individual sites and also between the sites. The synoptic conditions are characterized by a monsoon layer with south-westerly winds, on average about $1.9 \mathrm{~km}$ deep, and easterly winds above; the depth and strength of the monsoon flow show great day-to-day variability. Within the monsoon layer, a nocturnal low-level jet forms in approximately the same layer as the LLC. Its strength and duration is highly variable from night to night. This unique data set will allow us to test some new hypotheses about the processes involved in the development of LLCs and their interaction with the boundary layer and can also be used for model evaluation. 


\section{Introduction}

During the West African summer monsoon season, stratiform low-level clouds (LLCs), with typical cloud-base heights of only a few hundred metres above ground, frequently form over southern West Africa during nights that lack deep convection (Schrage et al., 2007; Knippertz et al., 2011; Schrage and Fink, 2012). According to van der Linden et al. (2015), their extent covers an area of about $800000 \mathrm{~km}^{2}$. As the clouds often persist long into the following day, they control the daytime radiative energy supply at the Earth's surface and, hence, influence the diurnal cycle of the atmospheric boundary layer $(\mathrm{ABL})$ and, thus, they considerably affect the regional climate (Knippertz et al., 2011; Hannak et al., 2017). Until now, high-quality observational data in this region have been lacking, and only a few model studies have been performed to investigate the temporal evolution and spatial distribution of LLCs in this region (e.g. Schuster et al., 2013; Adler et al., 2017). Based on these studies, several processes and conditions are expected to be relevant for the formation of LLCs including large-scale advection, orographic lifting, lifting related to gravity waves, latent heat release and vertical mixing of moisture due to shear-generated turbulence underneath the nocturnal low-level jet (LLJ). At Nangatchori in central Benin, Schrage and Fink (2012) found that about one-third of the precipitation-free nights were also LLC-free, despite the development of a LLJ. Schrage et al. (2007) concluded that cloudy nights in Parakou (central Benin) were found to occur in flow regimes with a strong south-westerly monsoon flow in the Guinea-Sudan zone, a weak African easterly jet (AEJ) and an enhanced tropical easterly jet (TEJ), while the reverse was the case for the clear nights. However, the lack of understanding of LLC formation has hitherto impeded any accepted explanation of the impact of large-scale monsoon circulation on observed synoptic variations in LLC extent in southern West Africa. Depending on the position of the AEJ during the season, shear between the lower part of the AEJ and the upper part of the usually south-westerly LLJ can also induce turbulent mixing between the moist monsoon air and dry harmattan layer above. The LLJ, which is linked to the north-south pressure gradient associated with the Saharan heat low (Parker et al., 2005; Lothon et al., 2008; Abdou et al., 2010), occurs frequently in this region and is found approximately in the same layer as the LLCs. It is unclear what role middle and upper-level clouds play in nocturnal cloud formation, their morning dissolution and in the growth of the cloud-topped daytime boundary layer in the following day (Leung et al., 2016). Aerosols, mainly emitted from the urban agglomerations along the West African coast, and their north-eastward transport with the monsoon flow, are also suspected to impact cloud characteristics in southern West Africa (Knippertz et al., 2015a). These previous studies suggest that the relevance of the various processes differs spatially but their respective contributions are neither fully understood nor verified by means of observations.
To address these issues, a concerted measurement campaign within the framework of the Dynamics-AerosolChemistry-Cloud Interactions in West Africa (DACCIWA) project was conducted in summer 2016. The overall goal of DACCIWA is to significantly advance the understanding of key interactions between surface-based emissions, atmospheric dynamics and chemistry, clouds, aerosols and the climate over West Africa, and to improve the capability to monitor and realistically model these interactions. (Knippertz et al., 2015b). To achieve these goals, measurements at three supersites, Kumasi (Ghana), Savè (Benin) and Ile-Ife (Nigeria; see Fig. 1a and b), were conducted and coordinated with airborne measurements from three research aircraft (Flamant et al., 2017). The observations were complemented by additional radiosoundings from existing national and reactivated African Monsoon Multidisciplinary Analysis (AMMA) networks (Parker et al., 2008). A detailed description of the field activities including details of the radiosonde campaign in summer 2016 is given by Flamant et al. (2017). The strategy for the ground-based measurements was to focus on the processes expected to be involved in LLC formation by applying a synergetic use of in situ and remote sensing observations. In situ measurements cover the near-surface meteorological conditions and the radiation and energy balance components at the Earth's surface. Remote sensing and in situ observations provide highly resolved thermodynamic conditions in the lowest kilometres, and radiosondes provide profiles of the whole troposphere. Besides radiosondes, which provide base and summit of LLC at given times, remote sensing systems allowed continuous monitoring of various cloud characteristics (cloud onset, base, top and base fraction). Bessardon et al. (2018) provide a detailed report about these measurements at the ground-based supersites and the available data. A description of the synoptic conditions that prevailed during the period of the DACCIWA campaign is given in Knippertz et al. (2017). In this paper, we give an overview of the meteorological conditions at the three ground-based supersites. In particular, we aim to (i) provide a characterization of the local conditions, (ii) investigate spatial and temporal variability, (iii) demonstrate the potential of the data set for investigating the dependence of the LLC formation on the synoptic and mesoscale conditions and (iv) provide some guidance for modellers. The paper is organized as follows. Section 2 describes the measurement sites and data used in this overview study. Section 3 surveys the near-surface and tropospheric conditions for the whole measurement period. Section 4 presents average diurnal cycles of energybalance components, near-surface meteorological variables and boundary-layer conditions, and Sect. 5 summarizes and concludes the main findings. 


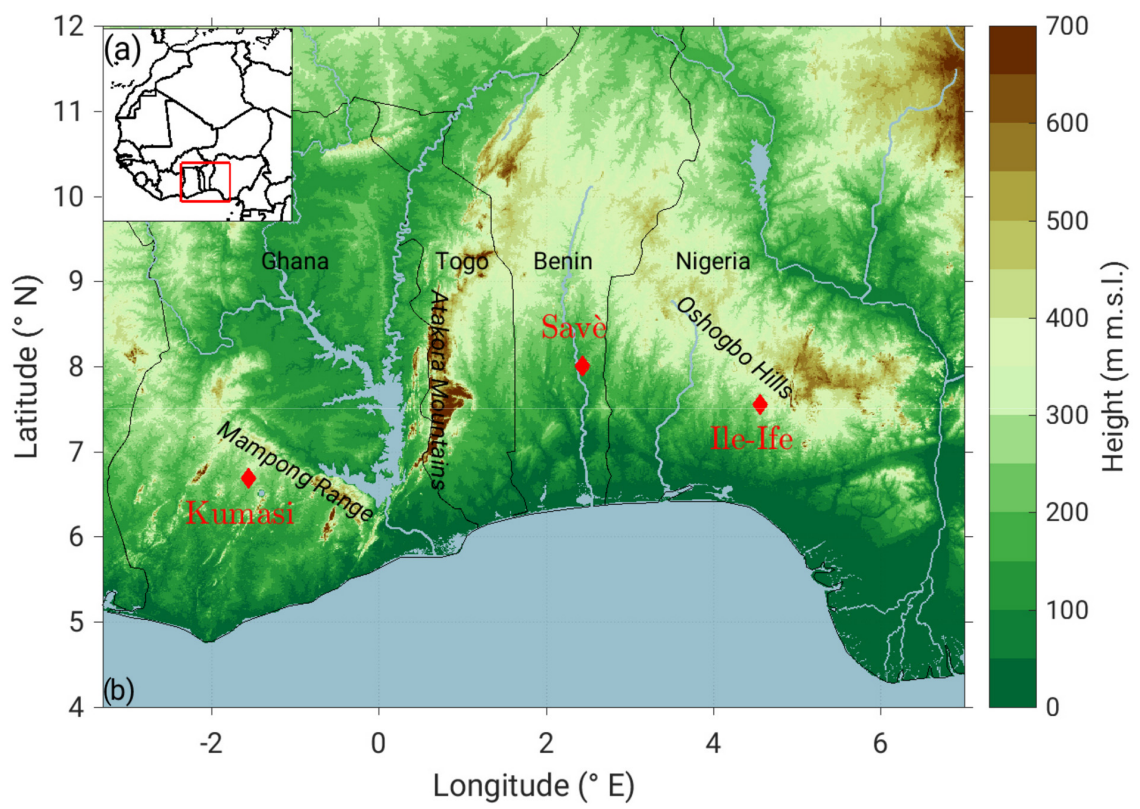

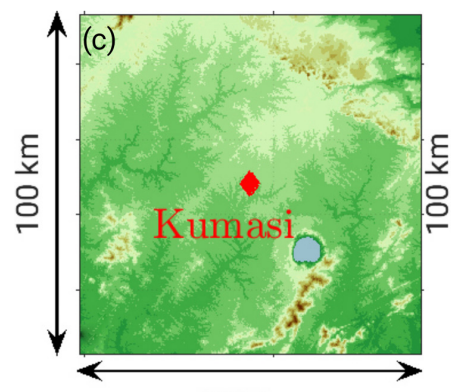

$100 \mathrm{~km}$

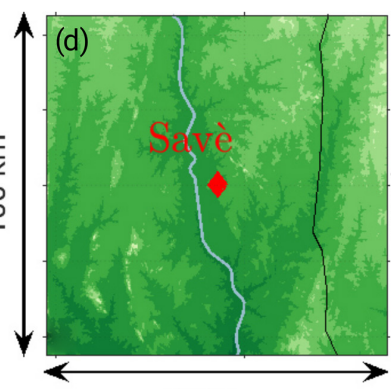

$100 \mathrm{~km}$

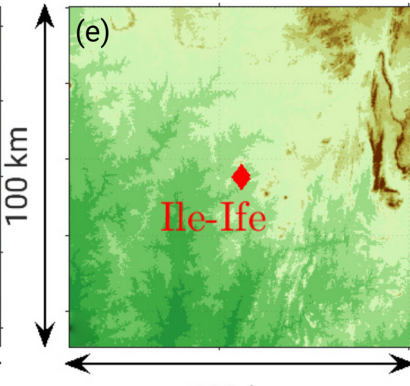

$100 \mathrm{~km}$

Figure 1. Location of the DACCIWA investigation area (red box) in West Africa (a) and orography in the investigation area with the locations of the three supersites Kumasi in Ghana, Savè in Benin and Ile-Ife in Nigeria (b). More detailed orography in the immediate surrounding of the three supersites Kumasi (c), Savè (d) and Ile-Ife (e). Solid lines indicate country borders with country names given in (b).

\section{Measurement sites and available observations}

The DACCIWA ground-based measurement campaign lasted from 14 June to 30 July 2016 and encompassed the 3 weeks of the airborne campaign (27 June to 16 July 2016), during which three European aircraft conducted research flights across Côte d'Ivoire, Ghana, Togo and Benin (Flamant et al., 2017). During the ground-based campaign, a comprehensive set of instruments was deployed at the three DACCIWA supersites (Fig. 1a and b), namely near the cities of Kumasi, Savè and Ile-Ife. The three stations are characterized by more (Kumasi, Ile-Ife) or less (Savè) hilly terrain but no significant mountains (Fig. 1c-e). The ground-based campaign consisted of continuous in situ and remote sensing observations as well as intensive observation periods, during which additional measurements were performed (mainly consisting of frequent radiosonde releases and flights from remotely piloted aerial systems). In total, 15 intensive observation periods (IOPs) were conducted. An overview of the complete set of instrumentation and measurements at the supersites is given by Bessardon et al. (2018). Here we restrict the description of instruments and measurements to those which allow surveying the meteorological conditions in the whole investigation area and thus spatial differences - that is, to observations that are available from at least two of the supersites. These are measurements of (i) the average near-surface meteorological parameters, (ii) the conditions in the atmospheric boundary layer, including cloud characteristics and (iii) the thermodynamics and dynamics in the whole troposphere. The instrumentation deployed at the different supersites and used in this paper is listed in Table $1 \mathrm{~b}$. The measurement heights of the near-surface observations and derived quantities (temperature, $T$; specific humidity, $q$; wind speed, $v$; wind direction, $\mathrm{WD}$; the radiation and energy balance components: shortwave upward radiation, $R$; shortwave downward radiation, $G$; longwave upward radiation, $L \uparrow$; longwave downward radiation, $L \downarrow$; total net radiation, $Q_{0}$; sensible heat flux, $H_{0}$; latent heat flux, $\mathrm{LE}_{0}$; soil heat flux, $B_{0}$; turbulent kinetic energy, TKE; flux Richardson number, $R f$ ) for the three supersites are listed in Table 1a. 
Table 1. (a) Coordinates and station heights in metres above sea level (ma.s.l.) and measurement heights in metres above ground level (m a.g.1.) of the energy balance station instruments at three supersites. $Q_{0}$ represents the total net radiation, $R$ the shortwave upward radiation and $G$ the shortwave downward radiation, $L \uparrow$ the longwave upward radiation and $L \downarrow$ the longwave downward radiation, $H_{0}$ the sensible heat flux, $\mathrm{LE}_{0}$ the latent heat flux, $B_{0}$ the soil heat flux, TKE the turbulent kinetic energy, $R f$ the flux Richardson number, $T$ the temperature, $q$ the specific humidity, $v$ the horizontal wind speed and WD the wind direction. (b) Equipment and manufacturers at the different sites.

\begin{tabular}{|c|c|c|c|}
\hline \multicolumn{4}{|l|}{ (a) } \\
\hline & Kumasi & Savè & Ile-Ife \\
\hline Latitude & $6^{\circ} 40^{\prime} 48.56^{\prime \prime} \mathrm{N}$ & $8^{\circ} 00^{\prime} 03.6^{\prime \prime} \mathrm{N}$ & $7^{\circ} 33^{\prime} 11.52^{\prime \prime} \mathrm{N}$ \\
\hline Longitude & $1^{\circ} 33^{\prime} 37.76^{\prime \prime} \mathrm{W}$ & $2^{\circ} 25^{\prime} 41.1^{\prime \prime} \mathrm{E}$ & $4^{\circ} 33^{\prime} 26.70^{\prime \prime} \mathrm{E}$ \\
\hline Height (m a.s.l.) & 266 & 166 & 274 \\
\hline 14 June: sunrise, sunset (UTC) & $05: 51,18: 22$ & $05: 33,18: 08$ & $05: 25,17: 59$ \\
\hline 30 July: sunrise, sunset (UTC) & $06: 00,18: 25$ & $05: 42,18: 11$ & $05: 34,18: 02$ \\
\hline Vegetation type & Short grassland & Grass and bushes (waist-deep) & Short grassland \\
\hline$G, R, L \downarrow, L \uparrow, Q_{0}$ (m a.g.l.) & 1.68 & 3 & 1.7 \\
\hline$H_{0}, \mathrm{LE}_{0}$, TKE, $R f$ (m a.g.l.) & 3.5 & 4 & 1.7 \\
\hline$B_{0}$ (m a.g.l.) & -0.08 & -0.02 & -0.02 \\
\hline$T, q$ (m a.g.l.) & 2 & 2 & 1.7 \\
\hline$v, \mathrm{WD}$ (m a.g.l.) & 3.5 & 4 & 1.7 \\
\hline Precipitation (m a.g.1.) & 1 & 1 & 1 \\
\hline \multicolumn{4}{|l|}{ (b) } \\
\hline Ceilometer & Campbell Scientific & Lufft & - \\
\hline Energy balance & $\begin{array}{l}\text { Kipp \& Zonen, } \\
\text { Campbell Scientific, LI-COR }\end{array}$ & $\begin{array}{l}\text { Kipp \& Zonen, } \\
\text { Gill, LI-COR }\end{array}$ & $\begin{array}{l}\text { Kipp \& Zonen, } \\
\text { Campbell Scientific, LI-COR }\end{array}$ \\
\hline Microwave radiometer & Radiometer Physics & Radiometer Physics & - \\
\hline Sodar & Sensor Technik Simach & Scintec & Metek \\
\hline (Tethered) radiosondes & Vaisala & Météomodem & GRAW \\
\hline UHF wind profiler & - & Degreane Horizon & - \\
\hline
\end{tabular}

Note that the number of data used for the composites of radiation and energy balance differs for the three sites due to instrument failure or quality-flagged periods, but for most of the quantities the data availability is $>80 \%$. The turbulent fluxes for the Savè site are calculated with the TK3.11 software (Mauder et al., 2013), for the Kumasi site according to Aubinet et al. (2012) and for Ile-Ife a customized eddy covariance program, which runs under the Campbell Scientific software Loggernet, was used.

To monitor the thermodynamics and dynamics of the atmospheric boundary layer, continuously running active (ultra-high-frequency (UHF) wind profiler in Savè, sodars in Kumasi, Savè and Ile-Ife) and passive (microwave radiometers in Kumasi and Savè) remote sensing systems were operated. Information on integrated water vapour (IWV) and liquid water path (LWP) from the radiometers is obtained with a retrieval algorithm provided by the University of Cologne
(Löhnert and Crewell, 2003; Löhnert et al., 2009). We trained the algorithm on a set of more than 12000 radiosonde profiles measured at Abidjan, Côte d'Ivoire, between 1980 and 2014.

Additionally, daily radiosoundings were performed at 06:00 UTC synoptic time. As it is convention that the radiosondes should be close to the tropopause at the nominal time, radiosondes were launched at 05:00 UTC at Savè and mainly between 05:30 and 06:00 UTC in Kumasi. This synoptic time was chosen because the LLC cover was expected to be most intense in the morning hours. The radiosounding data are used to characterize the monsoon and harmattan flows, AEJ and LLJ, to determine the tropospheric stratification and to ascertain cloud base and cloud top. The estimation of cloud-base and cloud-top height is achieved by applying the criteria of Wang and Rossow (1995), and is based on relative humidity, $\mathrm{RH}$. The low-level clouds are defined as 
the lowest cloud layer which fulfils the following three criteria: (i) the cloud layer is the layer where relative humidity is larger than $99 \%$, (ii) the cloud-layer depth must be larger than $100 \mathrm{~m}$ (this avoids misclassification of thin fog layers in Kumasi for four nights), and (iii) the cloud-top height is the level where RH equals $99 \%$ and RH shows a decrease of $3 \%$ in the $100 \mathrm{~m}$ layer above and has an at least $300 \mathrm{~m}$ deep layer of less than $99 \%$ of $\mathrm{RH}$ above.

The temporal evolution of cloud characteristics, i.e. cloud occurrence, base and cover, is obtained by ceilometers in Kumasi and Savè and net infrared radiation is available at all three sites. Net longwave radiation was found to be a good proxy for LLC occurrence. As ceilometers from different manufacturers (Lufft CHM15k in Savè and Campbell Scientific CS135 in Kumasi) were used, we expect discrepancies in the derived cloud-base height due to differences in the attenuated backscatter coefficient profiles and due to different manufacturer algorithms used to estimate cloud-base heights from the profiles. Cloud-base height of CS135 is mainly based on an increasing slope of the extinction profile and an extinction threshold (see CS135 manual: https:// s.campbellsci.com/documents/eu/manuals/cs135.pdf), while cloud-base height of CHM15k is determined with a threshold method (manufacturer Lufft, personal communication, 2016). A comparison of both ceilometers is described in Madonna et al. (2015). The detected number and temporal resolution of cloud-base heights provided from the different manufacturer algorithms differ (for manufacturers see Table 1b): in Savè, up to three cloud-base heights are output every minute, while in Kumasi, up to five cloud-base heights are reported every $10 \mathrm{~s}$. In order to increase the comparability for cloud-base height at both sites, we average cloud-base heights at Kumasi over 1 min intervals. For this purpose, we group the cloud-base heights in the $1 \mathrm{~min}$ intervals into $100 \mathrm{~m}$ vertical bins and assign the median value in the bin with the most number of cloud-base heights to the new 1 min cloudbase height.

\section{Near-surface and atmospheric conditions for the whole campaign}

The daily 06:00 UTC radiosoundings from Kumasi and Savè are used to generate 7-week mean profiles and time series of wind speed and direction (Fig. 2) as well as temperature and humidity (Fig. 3). These diagrams also indicate different phases of the monsoon season, which were distinguished by Knippertz et al. (2017) mainly based on the north-south precipitation difference between the coastal and the Sudanian-Sahelian zones. These are the pre-onset phase characterized by a rainfall maximum near the coast (before 21 June, phase 1), the post-onset phase during which the rainfall maximum occurred inland (22 June-20 July, phase 2), the wet westerly regime when the rainfall maximum shifted back to the coast (21-26 July, phase 3), and the recovery of the monsoon with a shift of the rainfall maximum inland (27 July until the end of the campaign, phase 4). A specific period within phase 2 is indicated as "vortex", during which an unusual development occurred (9-16 July): in the north, a cyclonic feature slowly propagated from eastern Mali to Cape Verde and in the south, an anticyclonic vortex tracked in the west-north-westerly direction along the Guinean coast (see Knippertz et al., 2017, for a more detailed description).

\subsection{Mean profiles}

Based on the mean wind profiles, we determine the average depth of the monsoon layer (Fig. 2, left). At both Kumasi and Savè, a distinct minimum in mean wind speed $\left(\leq 1.5 \mathrm{~m} \mathrm{~s}^{-1}\right)$ and a shift in wind direction from south-west to east occur at about $1.9 \mathrm{~km}$ above ground level (a.g.1.). This wind shear zone is often used to define the height of the monsoon layer (e.g. Fink et al., 2017). This height shows great variability with time as indicated by the increase in the standard deviation of the wind direction with height above the ground. The standard deviation of the wind direction is calculated according to Yamartino (1984). In the monsoon layer, a mean wind speed maximum of around $6 \mathrm{~m} \mathrm{~s}^{-1}$ at Savè and $8 \mathrm{~ms}^{-1}$ at Kumasi occurs at about $400 \mathrm{~m}$ a.g.1. This wind maximum is related to the LLJ that is usually still present at 06:00 UTC. Possible reasons for the greater mean wind-speed maximum in Kumasi compared to Savè will be investigated in Sect. 4. No distinct AEJ is visible in the mean wind profiles. This is because the AEJ was further to the north in the second half of the campaign and due to averaging over opposing winds; i.e. normally winds are easterly but westerly during the vortex period (Fig. 2, right). The standard deviation of the wind speed, which is more than $\pm 3 \mathrm{~m} \mathrm{~s}^{-1}$ in most of the layers at both sites, reflects strong day-to-day variations.

In the monsoon layer, the mean RH varies between 80 and $100 \%$ at both sites (Fig. 3, left). Above the monsoon layer, $\mathrm{RH}$ is about $7 \%$ at Kumasi. At Savè, $\mathrm{RH}$ has a minimum of $75 \%$ at about $3 \mathrm{kma.g} .1$. and increases to about $85 \%$ above. That means, on average, the atmosphere between 3 and $5 \mathrm{~km}$ a.g.l. at Kumasi is somewhat drier than Savè. This could be caused by convective activity upstream of Savè in Nigeria. Note that the standard deviation of RH, especially above $1 \mathrm{~km}$, is quite high (more than $\pm 10 \%$ ). The mean temperature profiles are rather similar at both sites, but the atmosphere at Savè is slightly warmer than at Kumasi. The mean gradient of the potential temperature is about $6 \mathrm{~K} \mathrm{~km}^{-1}$ between 0.5 and $2 \mathrm{~km}$ and about $5 \mathrm{~K} \mathrm{~km}^{-1}$ between 2 and $5 \mathrm{~km}$. As at the same time the mean gradient of the saturated equivalent potential temperature in these two layers is negative (not shown), the lower troposphere is conditionally unstable. At both sites, the standard deviation of the potential temperature is on the order of $\pm 1 \mathrm{~K}$. 
(a)
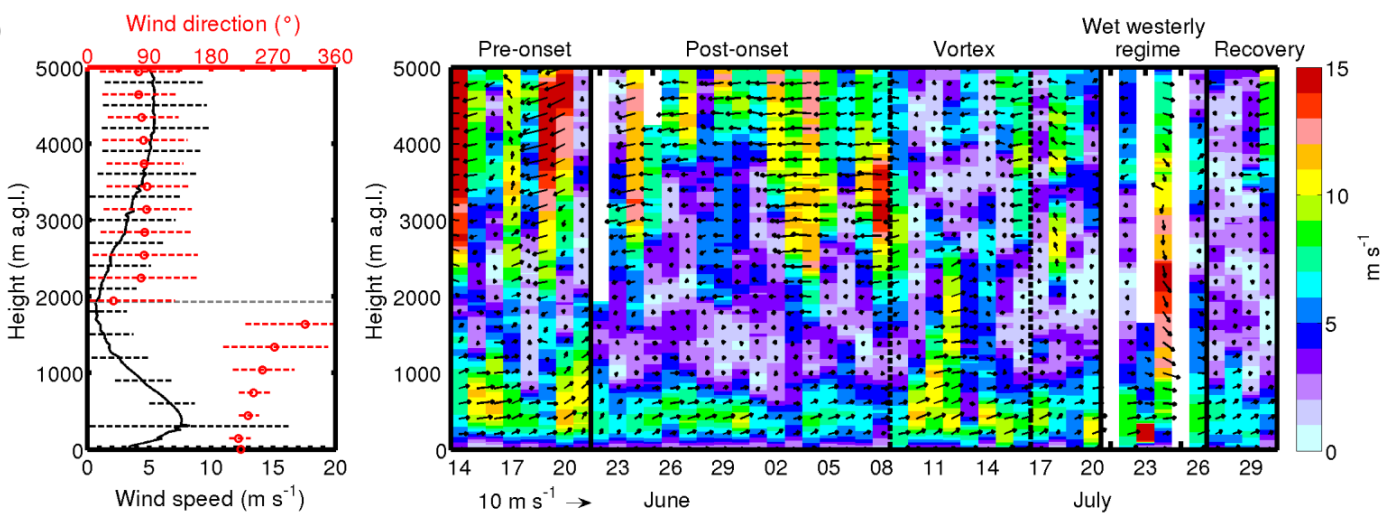

(b)
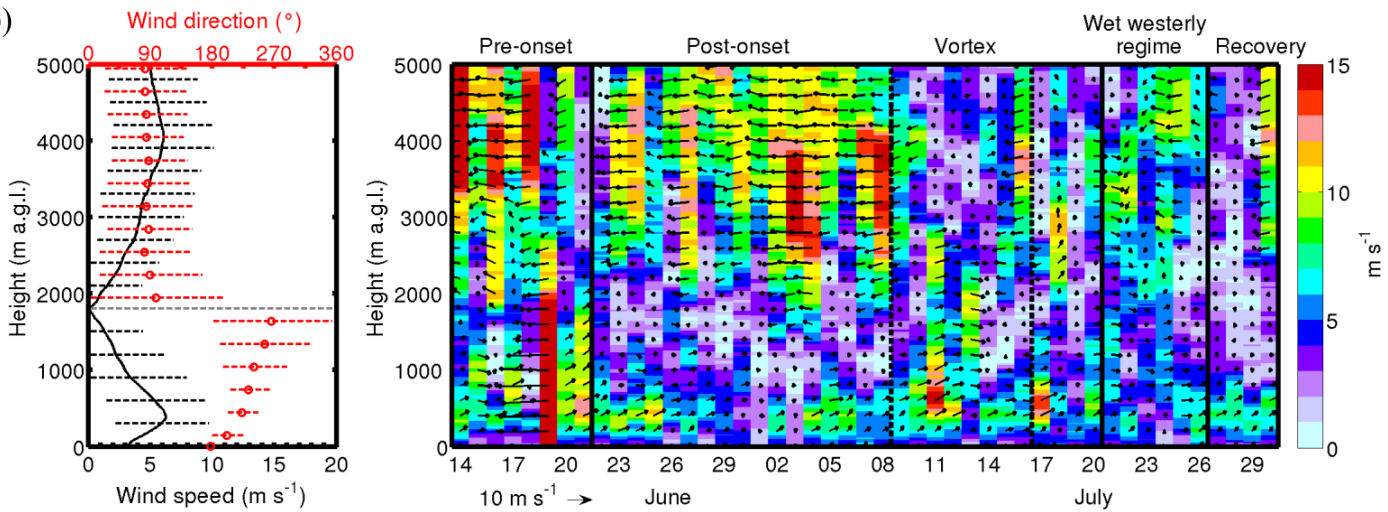

Figure 2. Mean profiles of wind speed (black solid line) and direction (red dots) including their standard deviations based on 06:00 UTC soundings at Kumasi (a) and Savè (b) on the left. The horizontal grey dashed line indicates the monsoon height. Times series of the horizontal wind vector (arrows) and absolute value of the wind speed (colour coded) at 06:00 UTC at Kumasi (a) and Savè (b) on the right. Different phases of the monsoon are indicated according to Knippertz et al. (2017).

\subsection{Day-to-day variability}

The large standard deviation of wind speed and direction can be explained by the atmospheric conditions on individual days (Fig. 2, right). In the harmattan layer above the monsoon layer, the AEJ is strong at both sites (mainly $>10 \mathrm{~m} \mathrm{~s}^{-1}$ ) during the first half of the observation period. On 11 July, a cyclonic vortex slowly propagates west-north-westwards from Gabon across the Gulf of Guinea and reaches Sierra Leone on 14 July (Knippertz et al., 2017). This causes largescale westerly winds up to about $3 \mathrm{~km}$ a.g.l. associated with a weakening and northward shift of the AEJ. This is also visible in the wind profiles at Savè (11-13 July) and Kumasi (11-14 July). After the vortex period, the mid-level easterly winds remain weak in the second half of the measurement period (15-30 July) at both sites. The large standard deviation in the monsoon layer partly arises from days that are affected by mesoscale convective systems (MCSs), e.g. on 19 June in Savè. As the wind profiles at 06:00 UTC result from the monsoon flow with the embedded LLJ, variations are caused by large-scale conditions and the characteristics of the LLJ. For example, a deep layer with high wind speed can be found on 21 June and 11 July at both sites.
The classical concept is that the monsoon layer is associated with south-westerly winds and moist air. This means that in general these qualities can be used to identify the monsoon layer. Using RH as an indicator for the moist layer, Fig. 3 shows that the day-to-day variability of the depth of the moist layer in the lower atmosphere varies by a factor of 2 or more and does not always coincide with the depth of the south-westerly wind layer. On the one hand, periods occurred when the moist layer was much deeper than the monsoon layer. These periods can often be assigned to MCSs passing the sites, accompanied by deep vertical mixing. For example, on 16 July a long-lived MCS (associated with cyclonic system "C" in Knippertz et al., 2017) passed Savè and on 26 July another MCS (associated with cyclonic system "J") affected Kumasi. On the other hand, the moist layer is significantly shallower than the monsoon layer during some periods. For example, the moist layer is only some hundred metres deep at Savè during the end of the pre-monsoon phase. During the last part of the post-onset phase, the moist layer at Savè is somewhat drier than the weeks before. This period is roughly related to the vortex period when dry air was transported northwards. 

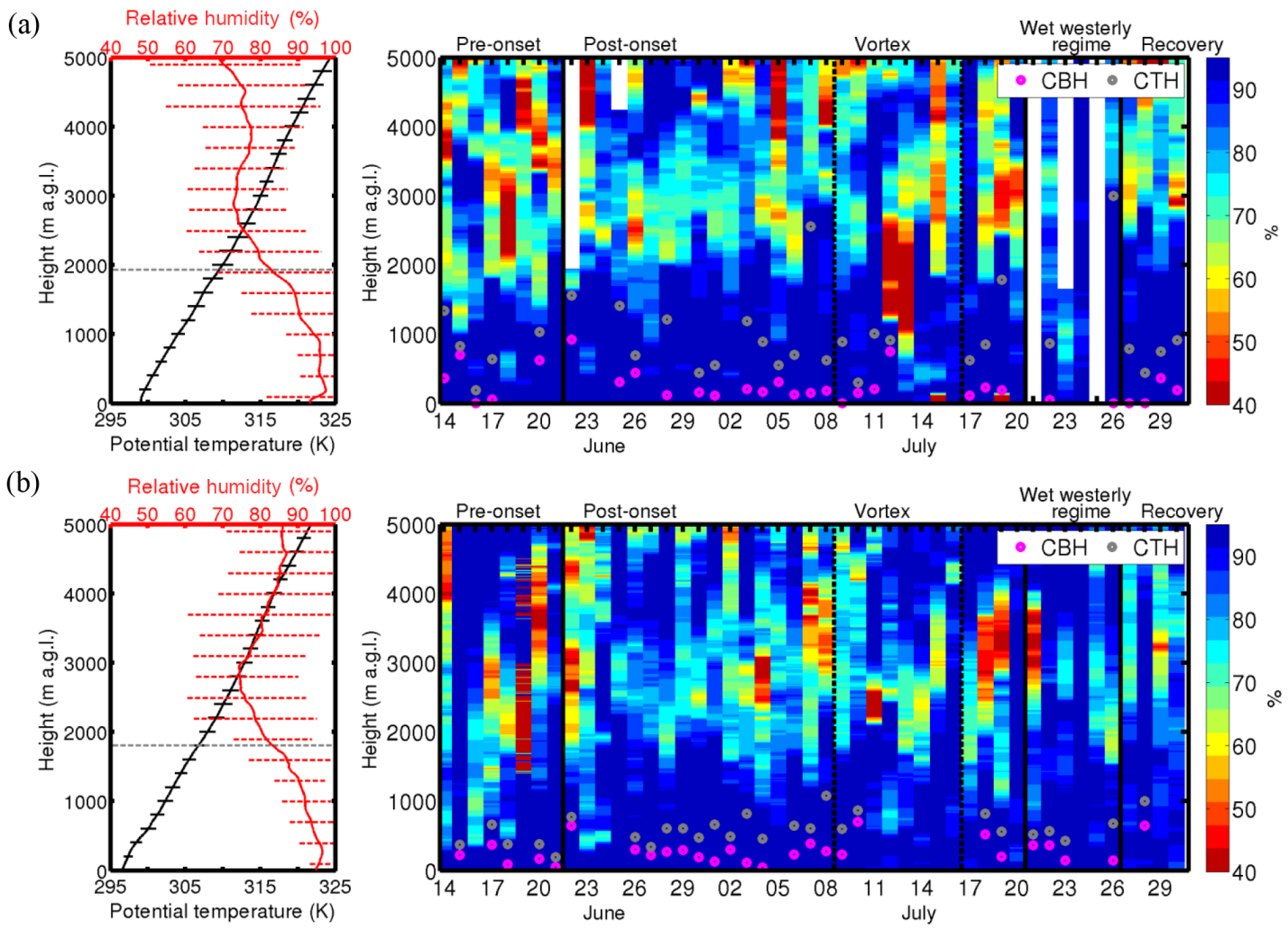

Figure 3. Mean profiles of relative humidity (red solid line) and potential temperature (black solid line) plus their standard deviations based on 06:00 UTC soundings at Kumasi (a) and Savè (b) on the left. The horizontal grey dashed line indicates the monsoon height. Times series of relative humidity (colour coded) at 06:00 UTC at Kumasi (a) and Savè (b) on the right. The pink and grey circles indicate cloud base and top estimated from the relative humidity profiles respectively. Different phases of the monsoon are indicated according to Knippertz et al. (2017).

Cloud-base and cloud-top heights estimated from RH profiles are also included in Fig. 3. Days with precipitation during the radiosounding were excluded from the analysis $(\mathrm{Ku}-$ masi: 11 and 24 July; Savè: 19 June, 20 and 24 July). The results show more frequent occurrence of LLCs at Kumasi $(88 \%)$ than Savè $(64 \%)$ at 06:00 UTC (purple dots in right panels of Fig. 3). In Savè, the median height for cloud base is $227 \mathrm{~m}$ a.g.l. and for cloud top is $587 \mathrm{~m}$ a.g.l., while in $\mathrm{Ku}-$ masi, the median heights are 137 and $692 \mathrm{~m}$ a.g.l. respectively. That means on average, LLCs in Kumasi are more often thicker than in Savè in the morning. As for the other parameters, there is evidence for a link between the monsoon phases and LLC occurrence and depth (see also Fig. 17 in Knippertz et al., 2017). During the pre-onset phase, LLCs are rather thin at both sites and less frequent at Savè. A higher LLC occurrence is observed during the post-onset monsoon phase, whereas dry air advection during the vortex period tends to reduce the LLC depth at Kumasi and even prevents LLC formation at Savè. For the remaining observation period, LLC formation is more sporadic, partly due to the increase in MCS events. Earlier work has already pointed to the fact the LLC forms in nights that lack deep convection, but farther north, cloud-free non-precipitative nights appear to occur more frequently (e.g. Schrage et al., 2007; Schrage and Fink, 2012). More information on the temporal evolution of cloud characteristics is given in Sect. 4.

The IWV, calculated from radiosoundings, shows higher values at Savè (median of $55 \mathrm{~kg} \mathrm{~m}^{-2}$ ) than at Kumasi (median of $50 \mathrm{~kg} \mathrm{~m}^{-2}$; Fig. 4c). This difference can be attributed to higher absolute moisture content at all levels. During the whole measurement period, no clear trends are visible for either Kumasi or Savè. A similar difference between the two sites exists in the IWV calculations based on microwave radiometer data (see Fig. 7). In Kumasi, the vortex period is accompanied by lower IWV values (Fig. 4c). This IWV decrease from about 50 to $34 \mathrm{~kg} \mathrm{~m}^{-2}$ could be attributed to dry air that is advected with the south-westerly winds (Fig. 2a) from the area of subsidence in the equatorial zone or even the southern hemisphere. Knippertz et al. (2017) report that the intrusion of dry air resulted in RH values as low as $10 \%$ in the middle troposphere over Abidjan in Côte d'Ivoire during this vortex phase. Farther east in Savè, the dry-air advection is much less pronounced and does not show up in the IWV (Figs. 2b and 4c). 


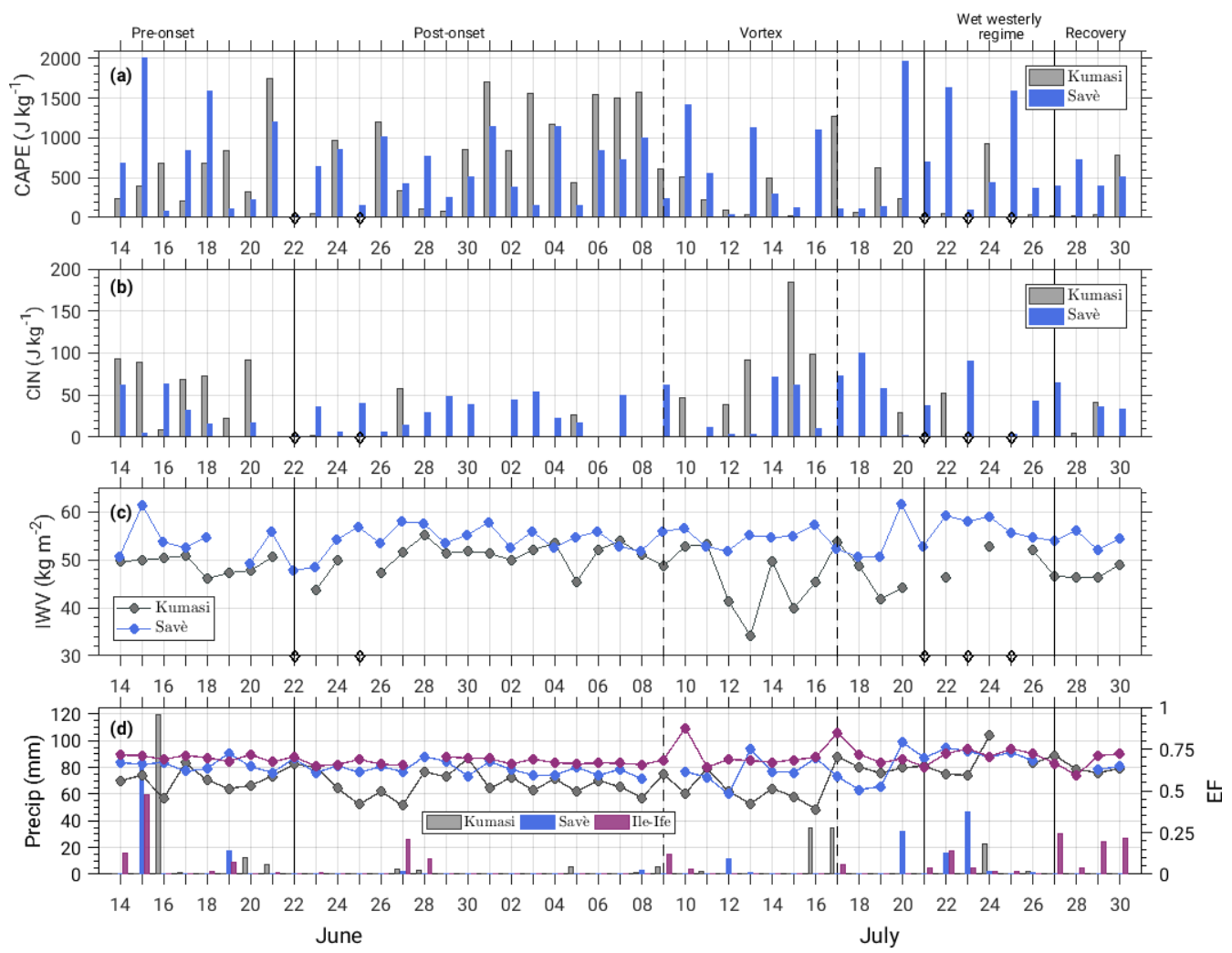

Figure 4. Time series of CAPE (a), CIN (b) and IWV (c) from the 06:00 UTC radiosonde data for Kumasi and Savè. Diurnal precipitation sum and evaporative fraction (EF) for Kumasi, Savè and Ile-Ife are shown in (d). Diamonds in (a), (b) and (c) indicate days with missing/incomplete radiosondes in Kumasi. Different phases of the monsoon are indicated according to Knippertz et al. (2017).

The convection-related parameters convective available potential energy (CAPE) and convective inhibition (CIN) are calculated from the soundings in Kumasi and Savè and shown in Fig. 4a and b. As the soundings are performed at 06:00 UTC, both quantities are calculated using the most unstable layer for lifting (Doswell III and Rasmussen, 1994), because surface-based parcels are inappropriate for lifting when a nocturnal surface inversion still exists. At both sites, CAPE shows strong day-to-day variability, ranging from about 100 to about $2000 \mathrm{~J} \mathrm{~kg}^{-1}$, with no clear dependence on the different monsoon phases (Fig. 4a). The median for the whole period for Kumasi is 434 and $508 \mathrm{~J} \mathrm{~kg}^{-1}$ for Savè. We attribute the large day-to-day variability of CAPE to convective precipitation events, which are typically followed by a decrease in CAPE as described by Schwendike et al. (2010) for the Sahel region and Schrage et al. (2006) for the Sudan region. High values of CIN (about 50 to $100 \mathrm{~J} \mathrm{~kg}^{-1}$ ) exist during the pre-onset phase (14-20 June) and at the end of the post-onset phase (about 14-21 July) of the monsoon (Fig. 4b). During these phases, stronger precipitation occurs (Fig. 4d). This link can be explained by a build-up of latent instability due to an accumulation of warm, moist air in lower layers in the presence of higher CIN values. This ultimately enhances the potential for stronger convection with heavy precipitation (e.g. Browning et al., 2007; Khodayar et al., 2010). The lowest CIN values $\left(<50 \mathrm{~J} \mathrm{~kg}^{-1}\right)$ are mainly observed during the post-onset phase, associated with little precipitation (Fig. 4d), typically generated by local convection. Fink et al. (2006) describe different types of rainfall associated with different CAPE and CIN values and intensities of precipitation for Parakou, which is about $130 \mathrm{~km}$ north of Savè. It is conceivable that the observed variability in CAPE and CIN and the related rainfall events fit the types of rainfall proposed by Fink et al. (2006), but this is left for future studies. The total amount of precipitation over the whole period ranges from $217 \mathrm{~mm}$ in Savè to $258 \mathrm{~mm}$ in Kumasi to $271 \mathrm{~mm}$ in Ile-Ife. It has to be kept in mind that all precipitation data are based on local measurements, which are not necessarily representative of the amount of convective precipitation in the area. However, the temporal distribution of precipitation in Savè shown in Fig. 4d agrees with that of the Savè X-band rain radar, which covers a diameter of up to $200 \mathrm{~km}$ (not shown).

The energy exchange at the surface is analysed using the evaporative fraction $\mathrm{EF}=\mathrm{LE}_{0} /\left(\mathrm{LE}_{0}+H_{0}\right)$, i.e. the ratio of the latent heat flux to the sum of latent and sensible heat fluxes or available energy (Fig. 4d). This quantity was calculated from $H_{0}$ and $\mathrm{LE}_{0}$ values, which were averaged for the 
time period from 09:00 to 15:00 UTC, i.e. when the fluxes are sufficiently high. A value of 1 indicates that all available energy goes into the latent heat flux, a value close to 0 means that the sensible heat flux dominates and at a value of 0.5 energy is equally distributed between sensible and latent heat fluxes. The median of EF is 0.58 in Kumasi, 0.64 in Savè and 0.69 in Ile-Ife; i.e. on average the majority of the available energy is transformed into latent heat flux - less in $\mathrm{Ku}-$ masi and more in Ile-Ife, although both are grassland sites. Although the $\mathrm{EF}$ at the different sites is rather constant over the campaign, some of the changes of $\mathrm{EF}$ are related to rain events; for example, the increases of EF in Savè from about 0.5 on 12 July to 0.75 on 13 July and from 0.6 on 19 July to 0.8 on 20 July. In Kumasi, a precipitation-generated EF increase from 0.4 to 0.7 is observed from 16 to $17 \mathrm{July}$. Similar behaviour of the evaporative fraction after precipitation events, when the soil is not saturated, is also reported by Kohler et al. (2010) and Lohou et al. (2014) for the AMMA field campaign.

\section{Diurnal cycles of near-surface and boundary-layer quantities}

The survey of the complete campaign reveals that the conditions differ considerably during the various monsoon phases as well as between the three sites. In this section, we present average diurnal cycles of the cloud characteristics followed by parameters considered relevant for LLC formation.

\subsection{LLC characteristics}

From the 1 min cloud-base heights obtained from ceilometer measurements, we calculate the cloud-base fraction for $30 \mathrm{~min}$ intervals for the lowest $1000 \mathrm{~m}$ above ground (Fig. 5a, b). Cloud-base fraction gives information on the number of cloud bases in a certain time period and height layer; i.e. a cloud-base fraction of $100 \%$ indicates that at all times in the $30 \mathrm{~min}$ interval is at least one cloud base detected in the lowest $1000 \mathrm{~m}$ a.g.l. Using a threshold of $100 \%$ for LLC detection, it is evident that LLCs develop during many nights at both sites, Kumasi and Savè. At 06:00 UTC, i.e. at the same time when daily radiosoundings were performed, LLCs occur less often in Kumasi (approximately $57 \%$ ) than in Savè (approximately $64 \%$ ), which differs from the finding based on the radiosonde data (LLCs occur more often in Kumasi than in Savè, Sect. 3.2). However, in Kumasi the results are very sensitive to the selected threshold for cloud-base fraction. Applying a threshold of $80 \%$, LLC occurrence increases to approximately $80 \%$ in Kumasi while it remains approximately the same in Savè. Nights without LLCs are found between 14 and 17 June at Savè, and around 23 and 24 June and 14-16 July at both sites. The latter period is roughly associated with the vortex occurrence, during which dry air masses are transported into the investiga- tion area (see Knippertz et al., 2017). Using a median cloudbase fraction of $100 \%$ as an indicator for the average onset of LLCs, LLCs approximately form at 00:00 UTC in Kumasi and 03:00 UTC in Savè (Fig. 5b). The onset of LLCs is accompanied by an increase in the median LWP to about $40 \mathrm{~g} \mathrm{~m}^{-2}$ at Savè and to about $50 \mathrm{~g} \mathrm{~m}^{-2}$ in Kumasi (Fig. $5 \mathrm{~d}$ ) and the net longwave radiation, $L_{\text {net }}=L \downarrow-L \uparrow$, increases to about $L_{\text {net }} \approx-10 \mathrm{Wm}^{-2}$ at both sites (Fig. 5e). Using a threshold of $L_{\text {net }} \approx-10 \mathrm{~W} \mathrm{~m}^{-2}$ as a proxy for the existence of LLCs, as indicated from the comparison of net longwave radiation with cloud-base fraction in Kumasi and Savè, LLCs in Ile-Ife already form at around 21:00 UTC.

From the cloud-base fraction we are unable to determine whether the cloud bases are all at the same height or distributed over several layers within the $1000 \mathrm{~m}$ layer. To get an idea of the vertical distribution of cloud-bases we also calculate the frequency distribution of cloud-base height by counting the number of days with at least one cloud base within a respective bin (bin size is 10 min duration and $20 \mathrm{~m}$ vertical range, Fig. 5c). As the backscatter coefficient profiles at Kumasi show no realistic values below around $50 \mathrm{~m}$ a.g.l. this layer is masked by the black bar in Fig. 5c. While there is some variability in cloud-base height during the campaign, we are able to distinguish those layers particularly favourable for cloud base occurrence. In Savè, surprisingly two layers are evident: one is at around $100 \mathrm{~m}$ a.g.l. and the other one at around $300 \mathrm{ma}$ a.g.l. Determining the cause for this will require detailed investigation. In Kumasi, cloud-base height occurs mainly in a layer around $200 \mathrm{~m}$ a.g.l. Radiosonde profiles at Kumasi indicate that cloud base also occurs at lower layers (Fig. 3a). Unfortunately, this cannot be verified by ceilometer data due to missing measurements.

At both sites, the cloud base starts to rise at approximately 07:00 UTC, i.e. about $1 \mathrm{~h}$ after sunrise (time of sunrise see Table 1a). During the rising period the cloud-base fraction remains close to $100 \%$ (Fig. 5b) and fluctuations in cloud-base height remain small for some time (Fig. 5c), indicating that the clouds are still stratiform. Eventually a transition to convective clouds occurs, indicated by a decrease in cloud-base fraction and a stronger fluctuation of cloud-base height. On average, the transition is approximately $2 \mathrm{~h}$ after the start of the rising period; however, we find large variability of several hours. Parallel to the cloud base rising around 07:00 UTC, the LWP at Savè reaches maximum values of up to 100 $125 \mathrm{~g} \mathrm{~m}^{-2}$ and $L_{\text {net }}$ decreases at both sites (Fig. 5d). Around midday, when the convective boundary layer is well developed, the cloud-base fraction decreased (to approximately $40 \%$ in Kumasi and $80 \%$ in Savè), $L_{\text {net }} \approx-40 \mathrm{~W} \mathrm{~m}^{-2}$ and the cloud-base height is at around $800 \mathrm{~m}$ a.g.l. In Ile-Ife, $L_{\text {net }}$ starts to decrease at 07:00 UTC indicating the dissolution of the LLCs at that site, too. Overall, the LLCs at the individual sites show considerable variability from day to day with respect to their time of formation and dissolution, cloud-base fraction, LWP and cloud-base height. The same finding holds when comparing the LLC conditions between the different 
(a)

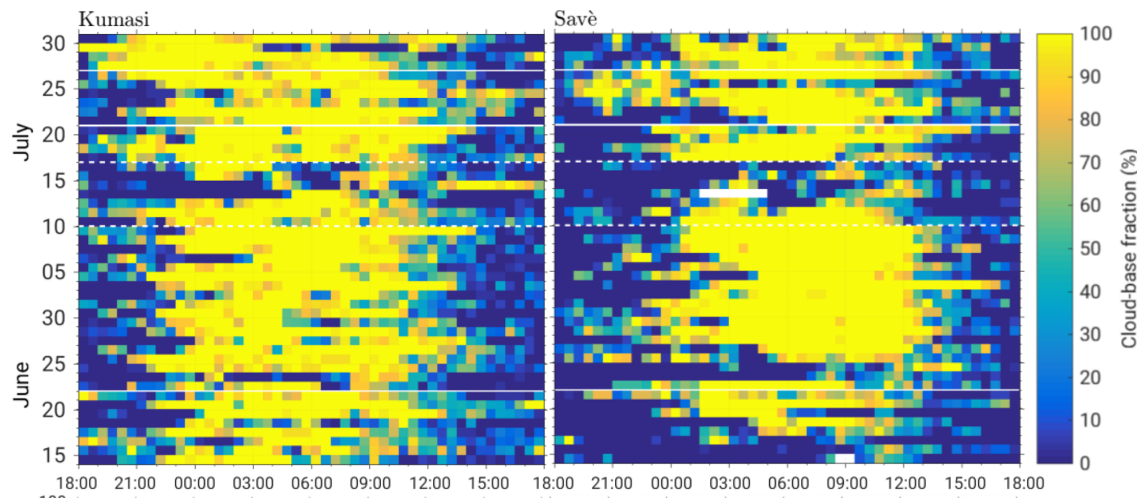

(b)

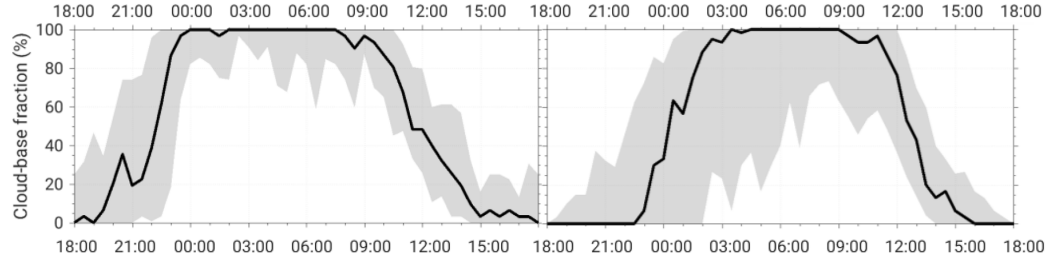

(c)

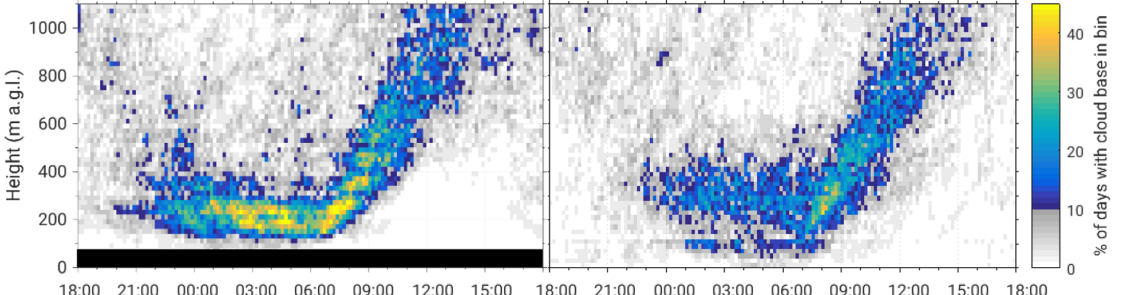

(d)

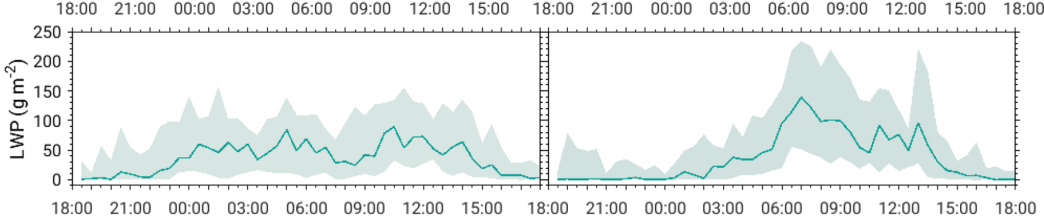

(e)

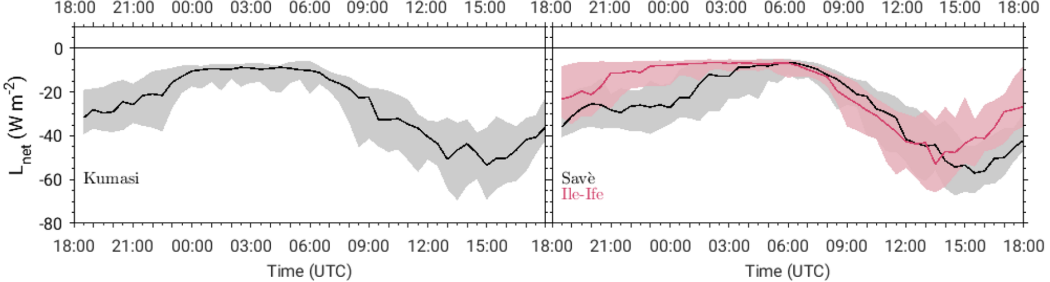

Figure 5. Daily resolved cloud-base fraction (a) and median (b) of clouds between 0 and $1000 \mathrm{~m}$ a.g.1. Distribution of cloud-base height occurrence during the whole 48 days period for the Kumasi (left) and Savè (right) sites (c). Cloud-base fraction and frequency distribution of cloud-base height are calculated from ceilometer data. White horizontal lines in (a) indicate different phases of the monsoon according to Knippertz et al. (2017). Median diurnal cycles of the liquid water path, LWP, from microwave radiometer (d) and net longwave radiation from surface measurements (e). The shaded areas in corresponding colours represent interquartile ranges.

supersites. Next, the diurnal cycles of quantities related to the LLC formation are presented.

\subsection{Radiation and energy balance at the surface}

Figure 6 presents composites of the diurnal cycles of the radiation and energy balance components for the three sites. Figure 6a indicates that the radiation balance components are quite similar at the three sites (Fig. 6a). The maximum median $G$ reaches up to approximately $550 \mathrm{~W} \mathrm{~m}^{-2}$ with an interquartile range of approximately $250 \mathrm{~W} \mathrm{~m}^{-2}$ at 13:00 UTC. This is caused by the considerable day-to-day variability of cloud cover. The median $R$ is about $110 \mathrm{~W} \mathrm{~m}^{-2}$, i.e. the albedo at the three supersites is approximately 0.2 , which is a typical value for grasslands (e.g. Oke, 1987). The longwave radiation shows much less variability.

At all three sites, the median $Q_{0}$ is of similar magnitude, at $400-450 \mathrm{~W} \mathrm{~m}^{-2}$ around midday (Fig. 6b). At this time, the median is accompanied by a significant interquartile range of $200 \mathrm{~W} \mathrm{~m}^{-2}$ (Fig. 6b), as is to be expected given the variability in the radiation components. The partitioning of the available energy $\left(Q_{0}-B_{0}\right)$ between $H_{0}$ and $\mathrm{LE}_{0}$, however, differs at the three sites. In Kumasi, the median $\mathrm{LE}_{0}$ is only slightly 

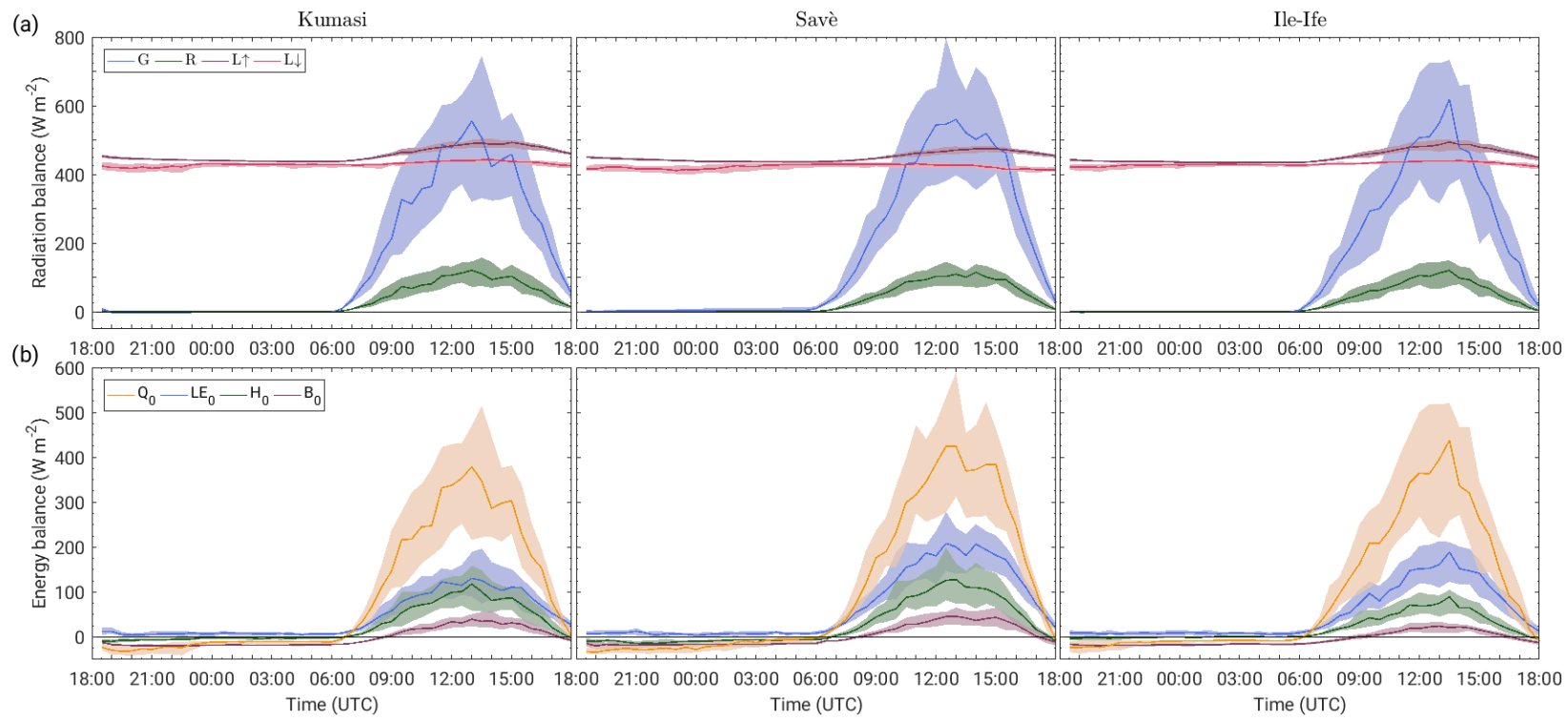

Figure 6. Median diurnal cycles of (a) radiation balance components (radiation: shortwave downward, $G$; shortwave upward, $R$; longwave downward, $L \downarrow$; longwave upward, $L \uparrow$ ) and (b) energy balance components (net radiation, $Q_{0}$; sensible heat flux, $H_{0}$; latent heat flux, LE $\mathrm{E}_{0}$; soil heat flux, $B_{0}$ ) for Kumasi (left), Savè (middle) and Ile-Ife (right). The shaded areas represent the interquartile ranges.

(a)

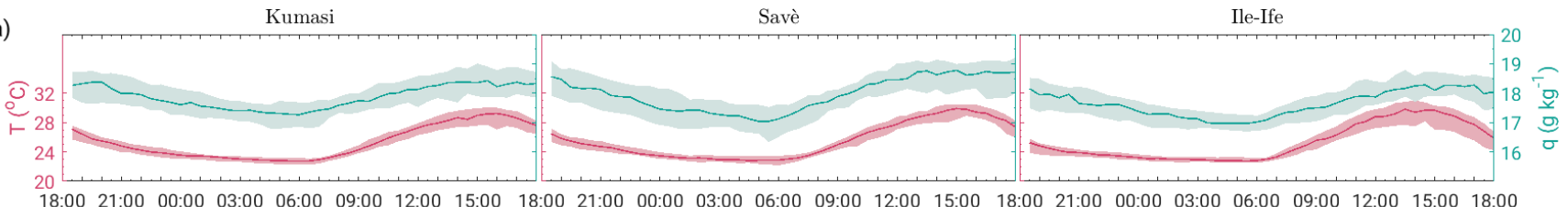

(b)

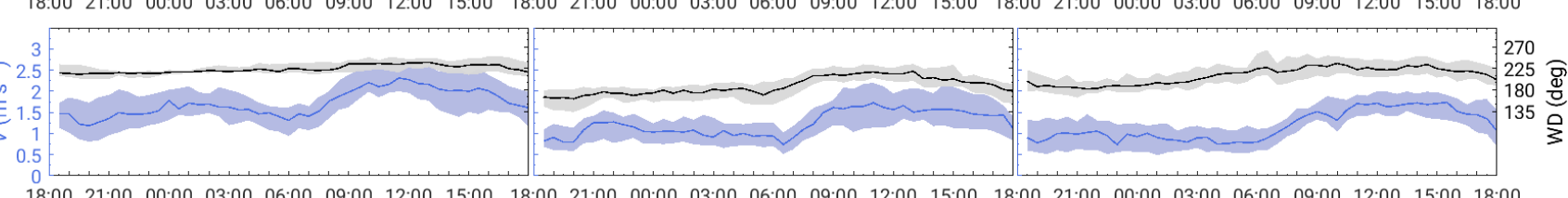

(c)

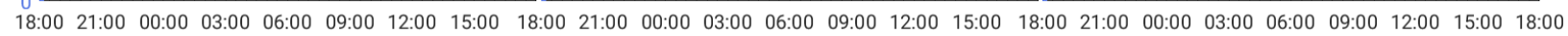
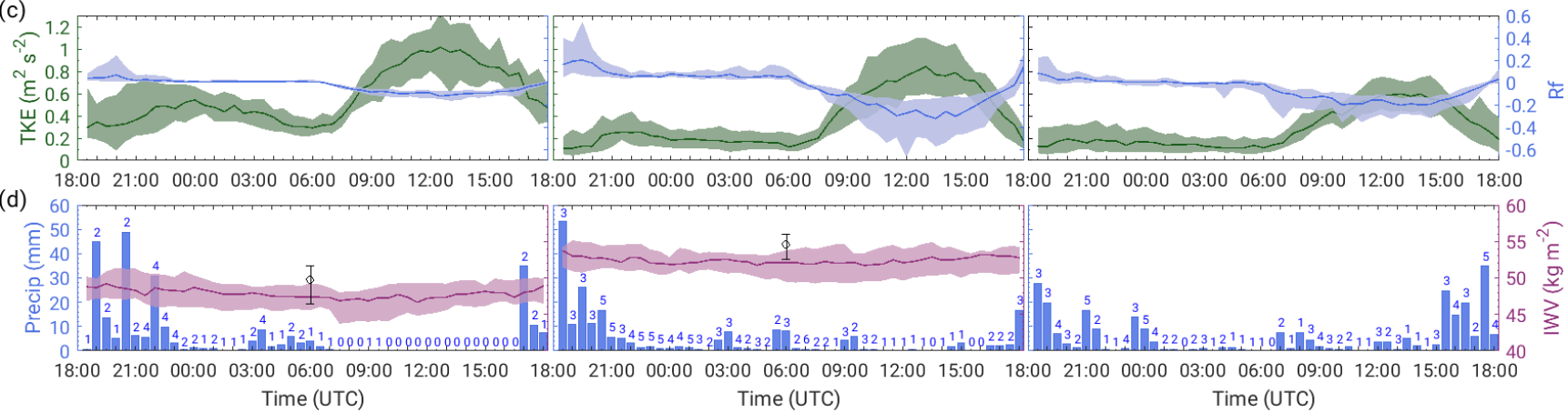

Figure 7. Median diurnal cycles of (a) specific humidity, $q$, and temperature, $T$; (b) wind speed, $v$, and wind direction, WD; (c) turbulent kinetic energy, TKE, and flux Richardson number, $R f$; and (d) integrated water vapour, IWV, for Kumasi (left), Savè (middle) and IleIfe (right). The shaded areas represent the interquartile ranges. In (d), the additional observation at 06:00 UTC indicates median IWV and interquartile ranges from radiosonde measurements at Kumasi and Savè, respectively, and half-hourly precipitation sums accumulated over the whole measurement period are shown (numbers indicate the number of days on which precipitation occurred). 
higher than $H_{0}$, which is consistent with a median evaporative fraction 0.58 (Sect. 3). In Savè, $\mathrm{LE}_{0}$ clearly dominates $H_{0}$; e.g. at noontime the median $\mathrm{LE}_{0}$ is about $200 \mathrm{~W} \mathrm{~m}^{-2}$, while the median $H_{0}$ is about $120 \mathrm{~W} \mathrm{~m}^{-2}$. At Ile-Ife, the median $\mathrm{LE}_{0}$ is also about $200 \mathrm{~W} \mathrm{~m}^{-2}$ and the median $H_{0}$ is only $100 \mathrm{~W} \mathrm{~m}^{-2}$ at noontime, resulting in the highest evaporative fraction (0.69) of all three sites. The accumulated daily evapotranspiration, $E_{0}$, derived from the median $\mathrm{LE}_{0}$ values, amounts to $1.3 \mathrm{~kg} \mathrm{~m}^{-2}$ at Kumasi, to $2.1 \mathrm{~kg} \mathrm{~m}^{-2}$ at Savè and to $1.6 \mathrm{~kg} \mathrm{~m}^{-2}$ at Ile-Ife. The turbulent fluxes at all three sites during daytime are associated with large interquartile ranges, due to both the strong day-to-day variability of available energy and because precipitation events modify the evaporative fraction from day to day (Fig. 4d). At all three sites, around sunset the median $Q_{0}$ becomes negative (around $-10 \mathrm{~W} \mathrm{~m}^{-2}$ ). The absolute value of $H_{0}$ is low at night (median between $H_{0}=-8.5 \mathrm{~W} \mathrm{~m}^{-2}$ in Savè and $-0.3 \mathrm{~W} \mathrm{~m}^{-2}$ in Ile-Ife), but by contributing to the compensation of the negative $Q_{0}, H_{0}$ contributes to the development of a stably stratified nocturnal surface layer, the decoupling of the daytime mixed layer from the surface layer and the development of an LLJ.

As expected for a tropical region during the monsoon season, the near-surface temperature exhibits only a moderate diurnal cycle with a median diurnal temperature range of about $6{ }^{\circ} \mathrm{C}$ at the three sites (Fig. 7a). The median temperature maximum of 29 to $30^{\circ} \mathrm{C}$ is reached in the early afternoon (about 15:00 UTC). The temperature's day-to-day variation is moderate, too; e.g. the interquartile range at 15:00 UTC is only about $2{ }^{\circ} \mathrm{C}$. The diurnal amplitude of the median $q$ is small as well, i.e. only about $1.0 \mathrm{~g} \mathrm{~kg}^{-1}$ in Kumasi, $1.2 \mathrm{~g} \mathrm{~kg}^{-1}$ in Ile-Ife and $1.8 \mathrm{~g} \mathrm{~kg}^{-1}$ in Savè (Fig. 7a). The median $q$ is highest at Savè (about $19 \mathrm{~g} \mathrm{~kg}^{-1}$ between 14:00 and 20:00 UTC). This might be attributed to the higher evapotranspiration (Fig. 6b). The microwave-derived IWV values (Fig. 7d) do not show a pronounced diurnal cycle, while precipitation reveals a strong time dependence (Fig. 7d). A period with more precipitation occurs between about 15:00 and 23:00 UTC. This time period is typical for local convective precipitation. The occurrence of local and patchy precipitation in the late afternoon is confirmed by the $\mathrm{X}$-band rain radar data at Savè (not shown).

When the surface layer becomes stably stratified around sunset, as indicated by the positive $R f$ at all sites (Fig. 7c), the near-surface wind speed and the TKE decrease (Fig. 7b and c). This decoupling of the surface layer from the mixed layer allows an LLJ to develop at all three sites (Fig. 8). The temporal cross section of median wind profiles is based on sodar measurements in Kumasi and Ile-Ife, while for Savè a combination of sodar and UHF wind profiler measurements are available. Affected by local noise production from a generator, the sodar at Kumasi did not reach high altitudes, especially at night (Fig. 8a). In Savè and Ile-Ife, the LLJ is well established at about 20:00 UTC (Fig. 8b and c). In Savè, the jet core can be found between 300 and $500 \mathrm{~m}$ a.g.l., and
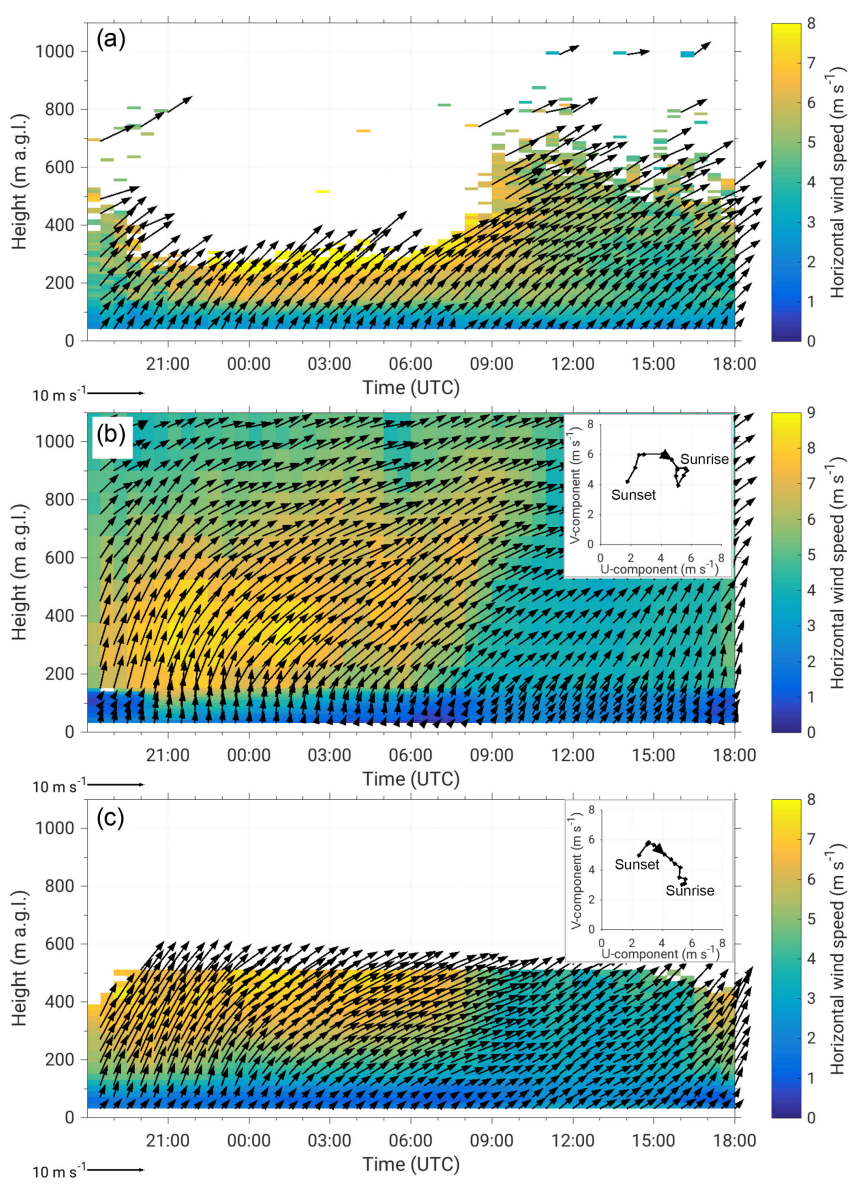

Figure 8. Median diurnal horizontal wind speed (colour coded) and horizontal wind vectors (arrows) for Kumasi (a), Savè (b) and IleIfe (c). Additionally, in (b) and (c) the hodograph from 18:00 UTC (approx. sunset) to 06:00 UTC (approx. sunrise) is shown with the wind components averaged over $1 \mathrm{~h}$ and between 200 and $600 \mathrm{~m}$ a.g.1.

the maximum median wind speed is about $8 \mathrm{~m} \mathrm{~s}^{-1}$ with a decrease in wind speed in the second half of the night. In Ile-Ife, the top of the LLJ is not covered by the sodar. Mean hodographs of the wind speed, calculated for the $200-600 \mathrm{~m}$ layer, show a clockwise turning of the wind in the course of the night from south-south-westerly at sunset to southwesterly at sunrise. The evolution of the nocturnal LLJ at the different sites is similar to observations described by Lothon et al. (2010) and Abdou et al. (2010) from AMMA. In the upper and lower shear zones of the LLJ, turbulence is expected (e.g. Banta et al., 2006), and gravity waves, similar to those at the top of drainage flows (Viana et al., 2010), are likely. Both are expected to have an impact on the LLC formation (Adler et al., 2017) and will be investigated in subsequent case studies.

During the night, the median near-surface wind speed and TKE are higher in Kumasi $\left(v \approx 1.5 \mathrm{~m} \mathrm{~s}^{-1}\right.$, TKE up to $\left.0.5 \mathrm{~m}^{2} \mathrm{~s}^{-2}\right)$ than at the two other sites $\left(v \approx 1.0 \mathrm{~m} \mathrm{~s}^{-1}\right.$, TKE 
up to $0.2 \mathrm{~m}^{2} \mathrm{~s}^{-2}$; Fig. 7 and c). Due to higher TKE, the surface layer in Kumasi is less stably stratified, i.e. the positive values of $R f$ are lower than at the two other sites. We assume that differences in LLJ are likely responsible for the differences in the near-surface conditions. A weaker LLJ results in weaker downward mixing (lower TKE). To seek an explanation we inspect the large-scale pressure gradient as a driving force for the LLJ and the orography: (i) there is evidence that the meridional pressure gradient is larger in the western part of the investigation area, i.e. the geostrophic wind has a larger zonal component at Kumasi, and (ii) the $700 \mathrm{~m}$ high Atakora Mountains in Togo (Fig. 1) cause a reduction of wind speed on the downstream side (as evident in simulations by Schuster et al., 2013), which also affects Savè. Shortly after sunrise, when the surface layer becomes unstable again (Fig. 7c), convective vertical mixing starts and momentum is transferred down to the surface again, as indicated by a TKE increase (Fig. 7c), and the LLJ starts to dissolve (Fig. 8). Simultaneously, near the ground the wind speed increases and the wind direction becomes more westerly (Fig. 7b).

\section{Summary and conclusions}

A unique, high-quality data set was obtained during the DACCIWA ground-based field campaign. This campaign was performed in southern West Africa from mid-June to the end of July 2016 with intensive ground-based measurements carried out at three supersites, Kumasi (Ghana), Savè (Benin) and Ile-Ife (Nigeria). The aim of this study is to provide a comprehensive overview of the conditions related to the development of nocturnal LLCs including their formation and the transition to convective clouds during the day. In order to allow for the comparison of conditions at the different sites, included here are only the observations which have been performed for at least two of the supersites. Two types of analyses are chosen: time series for the entire 7-week period and average diurnal cycles of meteorological parameters. The main findings are as follows.

The monsoon-layer depth, determined from the minimum in wind speed of the 06:00 UTC radiosoundings, is found to be at approximately $1.9 \mathrm{~km}$ on average. Within the monsoon layer, the mean wind direction is south-westerly and the mean wind-speed maximum, which occurs at about $400 \mathrm{ma}$ a.g.l., is about $6 \mathrm{~ms}^{-1}$ at 06:00 UTC in Savè and $8 \mathrm{~m} \mathrm{~s}^{-1}$ in Kumasi. The wind-speed profiles are characterized by the monsoon flow and the embedded LLJ, which still exists around 06:00 UTC. In the harmattan layer, easterly winds prevail with average wind-speed values of 6 to $7 \mathrm{~m} \mathrm{~s}^{-1}$. The day-to-day variability both in the monsoon and in the harmattan layer is high and mainly caused by the changes in the strength of the LLJ and position of AEJ respectively. Between 11 and 14 July, even westerly winds are present in the harmattan layer in conjunction with the passage of an anticyclonic vortex south of the investigation area
(Knippertz et al., 2017). The mean RH profiles show high values in the monsoon layer ( 80 to $95 \%$ ) and a minimum at about $3 \mathrm{~km}$ a.g.l. Above the monsoon layer, the RH on average was higher in Savè than in Kumasi. This is possibly caused by stronger convective activity upstream of Savè in Nigeria, resulting in deeper vertical mixing of humidity. The depths of the moist layer and the monsoon layer do not always coincide, indicating that on some days dry air intrusions from the harmattan into the monsoon layer occur and on other days a transport of humid air from the monsoon to the harmattan layer takes place. This means wind and moisture signals can be quite distinct, deviating from the classical concept of a monsoon layer with south-westerly winds and moist air.

The diurnal cycle of boundary-layer conditions at the three supersites reveals some interesting features. After sunset, which is at about 18:00 UTC in the investigation area, the surface layer becomes stably stratified, being less stable in Kumasi than in Savè and Ile-Ife, as indicated by a lower flux Richardson number. These spatial differences are also reflected in the near-surface TKE and wind-speed values, being higher during the night in Kumasi $\left(v \approx 1.5 \mathrm{~m} \mathrm{~s}^{-1}\right.$ and $\left.\mathrm{TKE} \approx 0.5 \mathrm{~m}^{2} \mathrm{~s}^{-2}\right)$ than at the two other sites $\left(v \approx 1.0 \mathrm{~m} \mathrm{~s}^{-1}\right.$ and $\mathrm{TKE} \approx 0.2 \mathrm{~m}^{2} \mathrm{~s}^{-2}$ ). After the surface layer becomes stably stratified, an LLJ develops at all three sites nearly every night, reaching maximum strength between 21:00 and 02:00 UTC. The LLJ dissipates gradually after sunrise at around 06:00 UTC.

At all three supersites, LLCs develop on most of the nights. The occurrence frequency depends on the instrument and method used for the detection of LLCs. Based on the 06:00 UTC radiosounding, LLCs occurred more often in Kumasi than in Savè, while the ceilometer measurements indicate the opposite. However, the latter is very sensitive to the applied criteria. The differences concerning cloud characteristics (LLC occurrence, cloud-base and cloud-top height) derived from radiosonde and ceilometer observations will be the subject of subsequent detailed investigation. Short episodes without LLCs are found at the beginning of the campaign in Savè, around 23-24 June, and around 14-16 July. Using a cloud-base fraction of $100 \%$ estimated from ceilometer measurements and net longwave radiation of $-1 \mathrm{~W} \mathrm{~m}^{-2}$ as an indicator for the average onset of LLCs, LLCs form at approximately 21:00 UTC in Ile-Ife, at 00:00 UTC in Kumasi and 03:00 UTC in Savè. In Savè, a two-layered structure of the cloud-base height is distinguishable with a maximum of cloud-base occurrence around 100 and $300 \mathrm{~m}$ a.g.l.; the reasons for this are currently being investigated. In Kumasi, the cloud-base height is mainly distributed around $200 \mathrm{~m}$ a.g.1. On average, the cloud base starts to rise around $1 \mathrm{~h}$ after sunrise, reaching heights around $800 \mathrm{~m}$ a.g.l. at noon. During this rising period, the clouds remain stratiform, eventually breaking up to form convective clouds. The times of LLC onset, breakup and transformation from stratiform to broken clouds vary considerably, all be- 
ing responsible for the strong day-to-day variability of the energy-balance components.

The measurements provide a unique data set to solve the two great enigmas, namely (1) what are the decisive processes and parameters for LLC formation (energy balance at the Earth's surface, LLJ, depth and strength of monsoon flow, harmattan and AEJ conditions, cold air advection and the presence of mid- and upper-level clouds), and (2) what determines their variability at temporal and spatial scales? To investigate these relationships and possible feedbacks, detailed process analysis will be performed in subsequent studies. Furthermore, this high-quality data set is invaluable for model evaluation and can be used to obtain the initial conditions for large eddy simulations dealing with cloud topped boundary layers as well as for reanalysis.

Data availability. After the DACCIWA embargo period, the data of the three supersites will be available on the SEDOO database (Brooks, 2016; Derrien et al., 2016; Handwerker et al., 2016; Jegede et al., 2016; Kohler et al., 2016; Wieser et al., 2016).

Competing interests. The authors declare that they have no conflict of interest.

Special issue statement. This article is part of the special issue "Results of the project "Dynamics-aerosol-chemistry-cloud interactions in West Africa" (DACCIWA) (ACP/AMT inter-journal SI)". It is not associated with a conference.

Acknowledgements. The DACCIWA project has received funding from the European Union Seventh Framework Programme (FP7/2007-2013) under grant agreement no. 603502. We also want thank the staff of NCAS (National Centre for Atmospheric Science), KIT (Karlsruhe Institute of Technology) and UPS (Université Toulouse) for helping install the equipment as well as those from KNUST in Kumasi and INRAB in Savè for allowing equipment to be used on their grounds and NCAS for providing the instrumentation deployed at Kumasi.

The article processing charges for this open-access

publication were covered by a Research

Centre of the Helmholtz Association.

Edited by: Ademe Mekonnen

Reviewed by: Ademe Mekonnen and one anonymous referee

\section{References}

Abdou, K., Parker, D. J., Brooks, B., Kalthoff, N., and Lebel, T.: The diurnal cycle of lower boundary-layer wind in the West African monsoon, Q. J. Roy. Meteor. Soc., 136, 66-76, https://doi.org/10.1002/qj.536, 2010.
Adler, B., Kalthoff, N., and Gantner, L.: Nocturnal low-level clouds over southern West Africa analysed using highresolution simulations, Atmos. Chem. Phys., 17, 899-910, https://doi.org/10.5194/acp-17-899-2017, 2017.

Aubinet, M., Vesala, T., and Papale, D. (Eds.): Eddy covariance. A practical guide to measurement and data analysis, Springer, Dordrecht, the Netherlands, https://doi.org/10.1007/978-94-0072351-1, 2012.

Banta, R. M., Pichugina, Y. L., and Brewer, W. A.: Turbulent velocity-variance profiles in the stable boundary layer generated by a nocturnal low-level jet, J. Atmos. Sci., 63, 2700-2719, 2006.

Bessardon, G., Brooks, B., Abiye, O., Adler, B., Ajao, A., Ajileye, O., Altstätter, B., Amekudzi, L. K., Aryee, J. N. A., Atiah, W. A., Ayoola, M., Babić, K., Bärfuss, K., Bezombes, Y., Bret, G., Brilouet, P.-E., Cayle-Aethelhard, F., Danuor, S., Delon, C., Derrien, S., Dione, C., Durand, P., Fosu-Amankwah, K., Gabella, O., Groves, J., Handwerker, J., Kalthoff, N., Kohler, M., Kunka, N., Jambert, C., Jegede, G., Lampert, A., Leclercq, J., Lohou, F., Lothon, M., Medina, P., Pätzold, F., Pedruzo Bagazgoitia, X., Reinares, I., Sharpe, S., Smith, V., Sunmonu, L. A., Tan, N., and Wieser, A.: A new high-quality dataset of the diurnal cycle of the southern West African atmospheric boundary layer during the Monsoon season - an overview from the DACCIWA campaign, Sci. Data, in preparation, 2018.

Brooks, B. J.: DACCIWA field campaign, Kumasi super-site, Instrumentation, SEDOO OMP, https://doi.org/10.6096/dacciwa.1663, 2016.

Browning, K., Blyth, A., Clark, P., Corsmeier, U., Morcrette, C., Agner, J., Bamber, D., Barthlott, C., Bennett, L., Beswick, K., Bitter, M., Bozier, K., Brooks, B., Collier, C., Cook, C., Davies, F., Deny, B., Engelhardt, M., Feuerle, T., Forbes, R., Gaffard, C., Gray, M., Hanken, R., Hewison, T., Huckle, R., Kalthoff, N., Khodayar, S., Kohler, M., Kraut, S., Kunz, M., Ladd, D., Lenfant, J., Marsham, J., McGregor, J., Nicol, J., Norton, E., Parker, D., Perry, D., Ramatschi, M., Roberts, H., Russel, A., Schulz, H., Slack, E., Vauhan, G., Waight, J., Watson, R., Webb, A., Wieser, A., and Zink, K.: The Convective Storm Initiation Project, B. Am. Meteorol. Soc., 88, 1939-1955, https://doi.org/10.1175/BAMS-88-12-1939, 2007.

Derrien, S., Bezombes, Y., Bret, G., Gabella, O., Jarnot, C., Medina, P., Piques, E., Delon, C., Dione, C., Campistron, B., Durand, P., Jambert, C., Lohou, F., Lothon, M., Pacifico, F., and Meyerfeld, Y.: DACCIWA field campaign, Savè super-site, UPS instrumentation; SEDOO OMP, https://doi.org/10.6096/DACCIWA.1618, 2016.

Doswell III, C. A. and Rasmussen, E. N.: The effect of neglecting the virtual temperature correction on CAPE calculations, Weather Forecast., 9, 625-629, https://doi.org/10.1175/15200434(1994)009<0625:TEONTV>2.0.CO;2, 1994.

Fink, A. H., Vincent, D. G., and Ermert, V.: Rainfall types in the West African Soudanian zone during the summer monsoon 2002, Mon. Weather Rev., 134, 2143-2164, https://doi.org/10.1175/MWR3182.1, 2006.

Fink, A. H., Engel, T., Ermert, V., van der Linden, R., Schneidewind, M., Redl, R., Afiesimama, E., Thiaw, W., Yorke, C., and Evans, M.: Mean climate and seasonal cycle, in: Meteorology of tropical West Africa: The forecasters' handbook, edited by: Parker, D. J. and Diop-Kane, M., John Wiley \& Sons, Ltd, Chich- 
ester, UK, 1-39, https://doi.org/10.1002/9781118391297.ch1, 2017.

Flamant, C., Knippertz, Fink, A.,, P., Akpo, A., Brooks, B., Chiu, C., Coe, H., Danuor, S., Evans, M., Jegede, O., Kalthoff, N., Konaré, A., Liousse, C., Lohou, F., Mari, C, Schlager, H., Schwarzenboeck, A., Adler, B., Amekudzi, L., Aeyee, J., Ayoola, M., Bessardon, G., Bower, K., Burnet, F., Catoire, V., Colomb, A., Fossu-Amankwah, K., Lee, J., Lothon, M., Manaran, M., Marsham, J., Meynadier, R., Ngamini, J.-B., Rosenberg, P., Sauer, D., Schneider, J., Smith, V., Stratmann, G., Voigt, C., and Yoboue, V.: The Dynamics-Aerosol-Chemistry-Cloud Interactions in West Africa field campaigns: Overview and research highlights, B. Am. Meteorol. Soc., 99, 83-104, https://doi.org/10.1175/BAMSD-16-0256.1, 2017.

Handwerker, J., Scheer, S., and Gamer, T.: DACCIWA field campaign, Savè super-site, Cloud and precipitation; SEDOO OMP, https://doi.org/10.6096/DACCIWA.1686, 2016.

Hannak, L., Knippertz, P., Fink, A. H., Kniffka, A., and Pante, G.: Why do global climate models struggle to represent low-level clouds in the West African summer monsoon?, J. Climate, 30, 1665-1687, https://doi.org/10.1175/JCLI-D-16-0451.1, 2017.

Jegede, O. O., Ayoola, M. A., Sunmonu, L. A., Ajao, A. I., and Babić, K.: DACCIWA field campaign, Ile Ife super-site, OAU instrumentation; SEDOO OMP, https://doi.org/10.6096/DACCIWA.1702, 2016.

Khodayar, S., Kalthoff, N., Wickert, J., Corsmeier, U., Morcrette, C. J., and Kottmeier, C.: The increase of spatial data resolution for the detection of the initiation of convection. A case study from CSIP, Meteorol. Z., 19, 179-198, https://doi.org/10.1127/09412948/2010/0439, 2010.

Kohler, M., Kalthoff, N., and Kottmeier, C.: The impact of soil moisture modifications on CBL characteristics in West Africa: A case-study from the AMMA campaign, Q. J. Roy. Meteor. Soc., 136, 442-455, https://doi.org/10.1002/qj.430, 2010.

Kohler, M., Kalthoff, N., Seringer, J., and Kraut, S.: DACCIWA field campaign, Savè super-site, Surface measurements; SEDOO OMP, https://doi.org/10.6096/DACCIWA.1690, 2016.

Knippertz, P., Fink, A. H., Schuster, R., Trentmann, J., Schrage, J. M., and Yorke, C.: Ultra-low clouds over the southern West African monsoon region, Geophys. Res. Lett., 38, https://doi.org/10.1029/2011GL049278, 2011.

Knippertz, P., Coe, H., Chiu, C., Evans, M., Fink, A. H., Kalthoff, N., Liousse, C., Mari, C., Allan, R., Brooks, B., Danour, S., Flamant, C., Jegede, O. O., Lohou, F., and Marsham, J. H.: The DACCIWA project: Dynamics-aerosol-chemistry-cloud interactions in West Africa, B. Am. Meteor. Soc., 96, 1451-1460, https://doi.org/10.1175/BAMS-D-14-00108.1, 2015a.

Knippertz, P., Evans, M., Field, P., Fink, A. H., Liousse, C., and Marsham, J. H.: The possible role of air pollution in climate change in West Africa, Nat. Clim. Change, 5, 815-822, https://doi.org/10.1038/nclimate2727, 2015b.

Knippertz, P., Fink, A. H., Deroubaix, A., Morris, E., Tocquer, F., Evans, M. J., Flamant, C., Gaetani, M., Lavaysse, C., Mari, C., Marsham, J. H., Meynadier, R., Affo-Dogo, A., Bahaga, T., Brosse, F., Deetz, K., Guebsi, R., Latifou, I., Maranan, M., Rosenberg, P. D., and Schlueter, A.: A meteorological and chemical overview of the DACCIWA field campaign in West Africa in June-July 2016, Atmos. Chem. Phys., 17, 10893-10918, https://doi.org/10.5194/acp-17-10893-2017, 2017.
Leung, W.-Y. H., Savre, J., Bender, F. A.-M., Komppula, M., Portin, H., Romakkaniemi, S., Sedlar, J., Noone, K., and Ekman, A. M. L.: Sensitivity of a continental night-time stratocumulus-topped boundary layer to varying environmental conditions, Q. J. Roy. Meteor. Soc., 142, 2911-2924, https://doi.org/10.1002/qj.2877, 2016.

Löhnert, U. and Crewell, S.: Accuracy of cloud liquid water path from ground-based microwave radiometry. 1: Dependency on cloud model statistics, Radio Sci., 38, 8041, https://doi.org/10.1029/2002RS002654, 2003.

Löhnert, U., Turner, D., and Crewell, S.: Ground-based temperature and humidity profiling using spectral infrared and microwave observations. Part I: Simulated retrieval performance in clear-sky conditions, J. Appl. Meteorol. Clim., 48, 1017-1032, https://doi.org/10.1175/2008JAMC2060.1, 2009.

Lohou, F., Kergoat, L., Guichard, F., Boone, A., Cappelaere, B., Cohard, J.-M., Demarty, J., Galle, S., Grippa, M., Peugeot, C., Ramier, D., Taylor, C. M., and Timouk, F.: Surface response to rain events throughout the West African monsoon, Atmos. Chem. Phys., 14, 388-3898, https://doi.org/10.5194/acp-14-3883-2014, 2014.

Lothon, M., Saïd, F., Lohou, F., and Campistron, B.: Observation of the diurnal cycle in the low troposphere of West Africa, Mon. Weather Rev., 136, 3477-3500, https://doi.org/10.1175/2008MWR2427.1, 2008.

Madonna, F., Amato, F., Vande Hey, J., and Pappalardo, G.: Ceilometer aerosol profiling versus Raman lidar in the frame of the INTERACT campaign of ACTRIS, Atmos. Meas. Tech., 8, 2207-2223, https://doi.org/10.5194/amt-8-2207-2015, 2015.

Mauder, M., Cuntz, M., Drüe, C., Graf, A., Rebmann, C., Schmid, H. P., Schmidt, M., and Steinbrecher, R.: A strategy for quality and uncertainty assessment of long-term eddycovariance measurements, Agr. Forest Meteorol., 169, 122-135, https://doi.org/10.1016/j.agrformet.2012.09.006, 2013.

Oke, T. R.: Boundary layer climates, Methuen Edn. 2, London, New York, 435 pp., 1987.

Parker, D., Burton, R., Diongue-Niang, A., Ellis, R., Felton, M., Taylor, C., Thorncroft, C., Bessemoulin, P., and Tompkins, A.: The diurnal cycle of the West African monsoon circulation, Q. J. Roy. Meteor. Soc., 131, 2839-2860, https://doi.org/10.1256/qj.04.52, 2005.

Parker, D. J., Fink, A., Janicot, S., Ngamini, J.-B., Douglas, M., Afiesimama, E., Agusti-Panareda, A., Beljaars, A., Dide, F., Diedhiou, A., Lebel, T., Polcher, J., Redelsperger, J.-L., Thorncroft, C., and Wilson, G. A.: The AMMA radiosonde program and its implications for the future of atmospheric monitoring over Africa, B. Am. Meteor. Soc., 89, 1015-1027, https://doi.org/10.1175/2008BAMS2436.1, 2008.

Schrage, J. M. and Fink, A. H.: Nocturnal continental low-level stratus over tropical West Africa: observations and possible mechanisms controlling its onset, Mon. Weather Rev., 140, 1794-1809, https://doi.org/10.1175/MWR-D-11-00172.1, 2012.

Schrage, J. M., Fink, A. H., Ermert, V., and Ahlonsou, E. D.: Three MCS cases occurring in different synoptic environments in the Sub-Sahelian wet zone during the 2002 West African monsoon, J. Atmos. Sci., 63, 2369-2382, https://doi.org/10.1175/JAS3757.1, 2006.

Schrage, J. M., Augustyn, S., and Fink, A. H.: Nocturnal stratiform cloudiness during the West African monsoon, Meteorol. At- 
mos. Phys, 95, 73-86, https://doi.org/10.1007/s00703-006-01947, 2007.

Schuster, R., Fink, A. H., and Knippertz, P.: Formation and maintenance of nocturnal low-level stratus over the southern West African monsoon region during AMMA 2006, J. Atmos. Sci., 70, 2337-2355, https://doi.org/10.1175/JAS-D-12-0241.1, 2013.

Schwendike, J., Kalthoff, N., and Kohler, M.: The impact of mesoscale convective systems on the surface and boundary layer structure in West Africa: case studies from the AMMA campaign, Q. J. Roy. Meteor. Soc., 136, 566-582, https://doi.org/10.1002/qj.599, 2010.

van der Linden, R., Fink, A. H., and Redl, R.: Satellite-based climatology of low-level continental clouds in southern West Africa during the summer monsoon season, J. Geophys. Res., 120, 1186-1201, https://doi.org/10.1002/2014JD022614, 2015.
Viana, S., Terradellas, E., and Yagüe, C.: Analysis of gravity waves generated at the top of a drainage flow, J. Atmos. Sci., 67, 39493966, https://doi.org/10.1175/2010JAS3508.1, 2010.

Wang, J. H. and Rossow, W. B.: Determination of cloud structure from upper-air observations, J. Appl. Meteor., 34, 2243-2258, https://doi.org/10.1175/15200450(1995)034<2243:DOCVSF>2.0.CO;2, 1995.

Wieser, A., Adler, B., and Deny, B.: DACCIWA field campaign, Savè super-site, Thermodynamic data sets; SEDOO OMP, https://doi.org/10.6096/DACCIWA.1659, 2016.

Yamartino, R. J.: A comparison of several "Single-Pass" Estimators of the Standard Deviation of Wind Direction, J. Climate Appl. Meteor., 23, 1362-1366, https://doi.org/10.1175/15200450(1984)023<1362:ACOSPE>2.0.CO;2, 1984. 